\title{
Theoretical study of geometry, stability and properties of Al and AISi nanoclusters
}

\author{
Ali Arab ${ }^{1} \cdot$ Mohaddeseh Habibzadeh $^{1}$
}

Received: 30 September 2015/Accepted: 11 November 2015/Published online: 22 January 2016

(c) The Author(s) 2016. This article is published with open access at Springerlink.com

\begin{abstract}
Geometry, stability, and properties of $\mathrm{Al}_{n}$ ( $n=1-13)$ and $\mathrm{Al}_{n} \mathrm{Si}_{m}(n+m=5-7)$ nanoclusters were investigated by density functional theory. We found that while geometry of some clusters change significantly by substituting of $\mathrm{Al}$ atom(s) with $\mathrm{Si}$ atom(s) the geometry of some others remain without significant variation. The relative stability of clusters was discussed on the basis of binding energy per atom, fragmentation energy, and second-order difference of cluster energies. Our results reveal that $\mathrm{Al}_{7}$ is the most stable cluster among pure clusters. For $\mathrm{Al}_{n} \mathrm{Si}_{m}$ clusters, it is observed that $\mathrm{Al}_{2} \mathrm{Si}_{3}(60 \% \mathrm{Si})$, and $\mathrm{Al}_{4} \mathrm{Si}_{2}(33.33 \% \mathrm{Si})$ are the most stable clusters. The reactivity of $\mathrm{Al}_{n}$ and $\mathrm{Al}_{n} \mathrm{Si}_{m}$ nanoclusters was also investigated on the basis of chemical hardness. The most important feature of chemical hardness is its oscillating behavior as a function of atomic percentage of $\mathrm{Si}$ indicating that the reactivity of $\mathrm{Al}_{n} \mathrm{Si}_{m}$ clusters strongly depends on the composition of cluster.
\end{abstract}

Keywords DFT · AlSi nanoclusters · Geometry · Stability $\cdot$ Chemical hardness

Electronic supplementary material The online version of this article (doi:10.1007/s40097-015-0185-7) contains supplementary material, which is available to authorized users.

Ali Arab

a.arab@semnan.ac.ir

1 Department of Chemistry, Semnan University, P.O. Box 35131-19111, Semnan, Iran

\section{Introduction}

The study of nanoclusters is an important subject of research due to their various applications in many fields [16]. By studying the properties of nanoclusters as a function of size, one hopes to learn how the bulk properties evolve and it can be providing important clues to the understanding of the mechanism of catalysis and other chemical properties [2, 3]. In both theoretical and experimental aspects, more studies on the clusters improve the processes of understanding their structures, electronic properties, and catalysis [4]. From experimental aspect, the development of laser vaporization technique has enabled experimentalists to produce and characterize atomic clusters of specific size and composition [2]. But synthesis of clusters is sometimes difficult because of (1) size selected clusters cannot be produced in sufficient quantities and (2) these are metastable, they would coalesce when brought in the vicinity of each other [2]. In addition, there is no experimental technique that can provide direct information on cluster geometry [2]. From theoretical aspect, on the other hand, geometry and many other properties of clusters have been successfully predicted and there are abundant reports in the literature that investigate the properties of clusters theoretically [7-11].

The aluminum nanoclusters have simple electronic structure and high electrical conductivity and, therefore, are important in catalytic processes such as hydrogenation and dehydrogenation reactions as well as fuel cell technology $[12,13]$. In recent years, $\mathrm{Al}$ and Al-based nanoclusters are the subject of numerous experimental and theoretical studies [14-20]. The reaction of $\mathrm{Al}$ clusters, $\mathrm{Al}_{n}$ $(n=7-24)$, formed by laser vaporization, with oxygen and ammonia has been studied using a fast flow reactor [14]. Reber et al. [15] have shown that some of the Al clusters 
are reactive toward even less reactive hydrocarbons. The interaction between $\mathrm{Al}$ clusters and several molecules such as $\mathrm{H}_{2} \mathrm{O}$ [4, 16], $\mathrm{H}_{2}$ [17, 18] $\mathrm{NH}_{2}$ [19] and $\mathrm{O}_{2}$ [20] was theoretically investigated.

Real catalysts mainly consist of a heterometallic or bimetallic system, which can enhance reactivity and selectivity [13]. Therefore, in theoretical study of clusters, much attention should be paid to the study of bimetallic clusters and their application in catalytic reactions. Al clusters are the most important lightweight materials for hydrogen adsorption and binding of hydrogen to the $\mathrm{Al}$ clusters can be significantly improved via doping. Kumar et al. [21] investigated the most stable structures and physical properties of $\mathrm{Al}_{12} \mathrm{Si}, \mathrm{Al}_{18} \mathrm{Si}$, and $\mathrm{Al}_{22} \mathrm{Si}$ clusters. They reported that $\mathrm{Si}$ impurity makes these clusters electronically closed shell and leads to a large gain in the binding energy. Majumder et al. [22] studied the equilibrium geometry and energetics of $\mathrm{Si}_{n}$ and $\mathrm{Si}_{n-1} \mathrm{Al}$ clusters using a combination of the density functional theory and molecular dynamics simulation under the local spin density (LSD) approximation. Their results revealed that clusters with $n=4,6,10$ show higher stability as compared to its neighboring clusters. Effect of aluminum impurity atoms on the structures and stabilities of neutral and ionic $\mathrm{Si}_{n}(-$ $n=2-21$ ) clusters have been investigated using full-potential linear-muffin-tin-orbital molecular-dynamics [23]. They found that most of the ground-state structures for neutral and ionic $\mathrm{Si}_{n} \mathrm{Al}(n=1-20)$ clusters can be obtained by substituting one $\mathrm{Si}$ atom of their corresponding $\mathrm{Si}$ clusters with an $\mathrm{Al}$ atom.

In this study, we performed a comprehensive and systematic DFT study on the properties of $\mathrm{Al}_{n}(n=1-13)$ and $\mathrm{Al}_{n} \mathrm{Si}_{m}(n+m=5-7)$ nanoclusters. Binding energy per atom, second-order difference of cluster energies, fragmentation energy, dipole moment $(\mu), \mathrm{Al}-\mathrm{Al}$ bond distance, and chemical hardness of nanoclusters were calculated and discussed. Variations of geometry, stability and reactivity of nanoclusters were also analyzed as a function of cluster size as well as cluster composition.

\section{Computational methods}

The geometry of all clusters including $\mathrm{Al}_{n}(n=1-13)$ and $\mathrm{Al}_{n} \mathrm{Si}_{m}(n=4-6, m=1-3, n+m=5-7)$ were optimized without any constraint using the functionals of Becke' three-parameter hybrid exchange functional [24] and the Lee-Yang-Parr correlation functional [25] (B3LYP) and $6-31+G^{*}$ basis set. Effect of basis set was also studied on the electronic properties of most stable structures considering $6-31+G^{* *}$ and $6-311+G^{*}$ basis sets. All calculations were done by the Gaussian03 package [26]. The B3LYP hybrid density functional has been used abundantly for the study of Al clusters. For example, B3LYP functional has been used for the study of structure and electronic properties of $\mathrm{Al}_{n} \mathrm{As}$ clusters [7]. Guo et al. [13] employed B3LYP functional to investigate the structure of $\mathrm{Al}_{n} \mathrm{~V}$ clusters and their interaction with molecular hydrogen. Dissociation of hydrogen on small Al clusters has been studied through B3LYP functional [17]. In addition, all calculations involved the determination of vibrational frequencies at the same level of theory and basis set for the validation of the local energy minima of each optimized structure as well as zero point energy correction.

\section{Results and discussion}

\section{$\mathrm{Al}_{n}(n=1-13)$ clusters}

To find the most stable structure of $\mathrm{Al}_{n}$ clusters we optimized each cluster, initiating with different possible structures as input file, at three spin multiplicities of, 1, 3, and 5 for clusters with even electrons number and 2, 4, and 6 for clusters with odd electrons number. Figure 1 presents the most stable structure of $\mathrm{Al}_{\mathrm{n}}$ clusters while the corresponding spin multiplicities (Ms) and dipole moments $(\mu)$ are summarized in Table 1. Other higher energy structures along with the corresponding spin multiplicities as well as relative energies $\left(E_{\mathrm{r}}\right)$ are collected as supporting information in table S.1. The relative energies are calculated by subtracting the energy of the most stable structure from the energy of a structure in the series. The calculated vibrational frequencies of most stable structures of $\mathrm{Al}_{n}$ clusters computed at B3LYP/6-31 $+G^{*}$ level of theory are collected as supporting information in table S.2. The structures reported in Fig. 1 are in agreement with those reported in the literature [2, 4, 7, 17]. It has been shown that for $\mathrm{Al}_{n}$ clusters up to five atoms the structures are planar and for clusters containing 6-13 atoms the structures become three dimensional $[2,4,7,17]$. For $\mathrm{Al}_{6}$ cluster we found that the most stable structure is trigonal prism geometry with $\mathrm{Ms}=3$ while the octahedral geometry with $\mathrm{Ms}=1$ is only $0.01 \mathrm{eV}$ less stable. Pino et al. [17] obtained different geometries as the most stable structure of $\mathrm{Al}_{6}$ depending on the method used for optimization. With B3LYP they obtained trigonal prism geometry with $\mathrm{Ms}=3$ as the most stable structure while the octahedral geometry with $\mathrm{Ms}=1$ is only $0.006 \mathrm{eV}$ less stable. With $\operatorname{CCSD}(\mathrm{T})$, on the other hand, they obtained octahedral geometry with $\mathrm{Ms}=1$ as the most stable structure while the trigonal prism geometry with $\mathrm{Ms}=3$ is $0.162 \mathrm{eV}$ less stable. For $\mathrm{Al}_{13}$ cluster, we obtained distorted icosahedron geometry with $\mathrm{Ms}=2$ as the most stable structure in agreement with some reported results $[2,7]$. Some authors 
Fig. 1 The most stable structures of $\mathrm{Al}_{n}$ ( $n=2-13)$ clusters computed at B3LYP/6-31 $+G^{*}$ level of theory

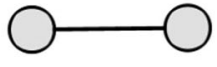

$\mathrm{Al}_{2}$

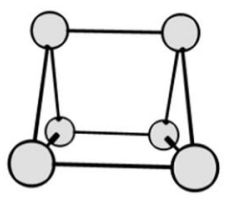

Al6

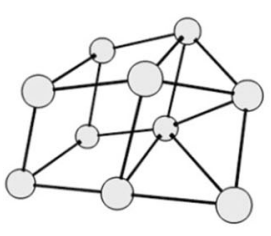

Alıo

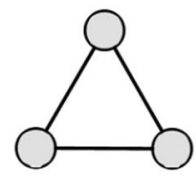

$\mathrm{Al} 3$

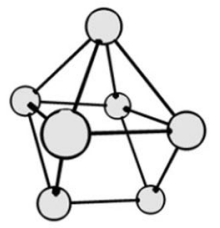

$\mathrm{Al} 7$

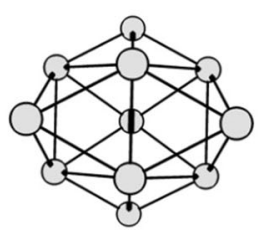

Al11

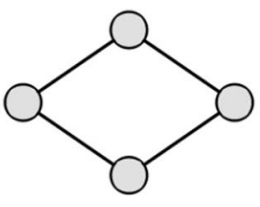

$\mathrm{Al}_{4}$

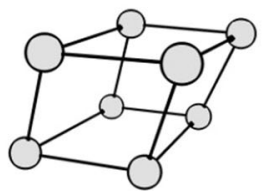

$\mathrm{Al} 8$

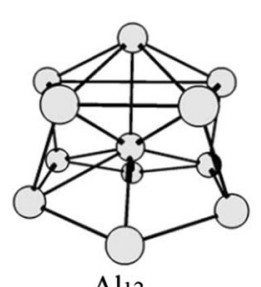

Al12

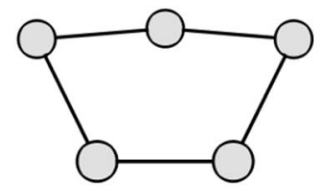

$\mathrm{Al} 5$

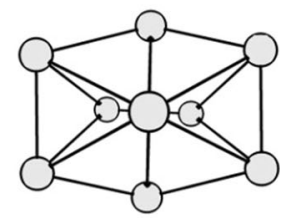

$\mathrm{Al} 9$

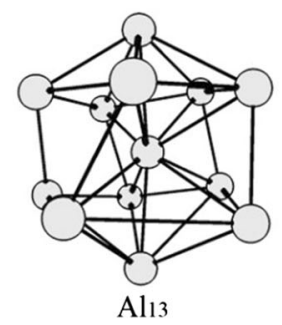

Table 1 The spin multiplicity and dipole moment of most stable $\mathrm{Al}_{n}$ clusters presented in Fig. 1

\begin{tabular}{lllllllllllll}
\hline Cluster & $\mathrm{Al}_{2}$ & $\mathrm{Al}_{3}$ & $\mathrm{Al}_{4}$ & $\mathrm{Al}_{5}$ & $\mathrm{Al}_{6}$ & $\mathrm{Al}_{7}$ & $\mathrm{Al}_{8}$ & $\mathrm{Al}_{9}$ & $\mathrm{Al}_{10}$ & $\mathrm{Al}_{11}$ & $\mathrm{Al}_{12}$ & $\mathrm{Al}_{13}$ \\
\hline Ms & 3 & 2 & 3 & 2 & 3 & 2 & 1 & 2 & 1 & 2 & 1 & 2 \\
$\mu$ /Debye & 0.000 & 0.000 & 0.002 & 0.520 & 0.004 & 0.420 & 0.001 & 0.180 & 0.420 & 0.104 & 0.081 & 0.440 \\
\hline
\end{tabular}

reported regular icosahedron geometry $\left(\mathrm{I}_{\mathrm{h}}\right.$ symmetry) as the most stable structure for $\mathrm{Al}_{13}$ cluster $[4,12]$.

According to the results of Table 1 the doublet spin state is the lowest in energy (most stable state) for all $\mathrm{Al}_{n}$ clusters with odd number of atoms. For $\mathrm{Al}_{n}$ clusters with even number of atoms, on the other hand, the triplet spin state is the lowest in energy for $\mathrm{Al}_{2}, \mathrm{Al}_{4}, \mathrm{Al}_{6}$ and the singlet spin state is the lowest in energy for $\mathrm{Al}_{8}, \mathrm{Al}_{10}$ and $\mathrm{Al}_{12}$. Cox et al. [27] experimentally found that the spin multiplicity of small Al clusters $(n<10)$ is 2 for clusters with odd number of atoms and 3 for clusters with even number of atoms. Interestingly, we observed that increasing the spin multiplicity of clusters to 4,5 , and 6 do not affect final structure of the clusters; however, clusters with higher spin multiplicity are very unstable energetically (in some cases more than $2 \mathrm{eV}$ ). Results of Table 1 show that the dipole moment of $\mathrm{Al}$ clusters strongly depend on the size and structural symmetry of the clusters which is in agreement with the results of references [2, 28, 29]. It has been reported that clusters with odd number of atoms are less symmetric and have larger values of dipole moment while clusters with even number of atoms are more symmetric and have smaller values of dipole moment [2]. Among $\mathrm{Al}_{n}$ clusters; $\mathrm{Al}_{5}, \mathrm{Al}_{7}, \mathrm{Al}_{10}$, and $\mathrm{Al}_{13}$ have the highest values of dipole moment.
For the most stable $\mathrm{Al}_{n}$ clusters we investigate some important properties as a function of cluster size. The relative stability of the $\mathrm{Al}_{n}$ clusters has been investigated according to the binding energy per atom, secondorder difference of cluster energies, and fragmentation energy.

The binding energy per atom of clusters was calculated according to the Eq. 1.

$E_{b}=\frac{n E(\mathrm{Al})-E\left(\mathrm{Al}_{n}\right)}{n}$

where in this equation $n$ is the number of $\mathrm{Al}$ atoms in cluster, $E(\mathrm{Al})$ is the energy of $\mathrm{Al}$ atom in the most stable state and $E\left(\mathrm{Al}_{n}\right)$ is the energy of the most stable $\mathrm{Al}_{n}$ cluster. Variation of binding energy per atom as a function of cluster size is shown in Fig. 2a. According to this figure the binding energy per atom increases monotonically to the maximum value of $2.01 \mathrm{eV}$ for $\mathrm{Al}_{13}$ cluster while is smaller than the $\mathrm{Al}$ bulk cohesive energy of $3.39 \mathrm{eV}$ [2]. Distinctive regions which separated from each other at $n=3,7$, and 10 are also observed in Fig. 2a.

To gain better insight about the relative stability of clusters, it is more instructive to analyze the second-order difference of cluster energies $\left(\Delta_{2} E\right)$ and fragmentation 
(a)

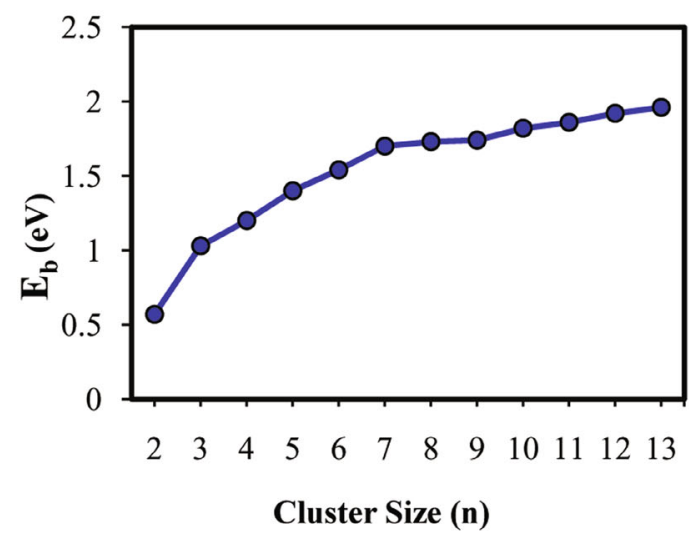

(c)

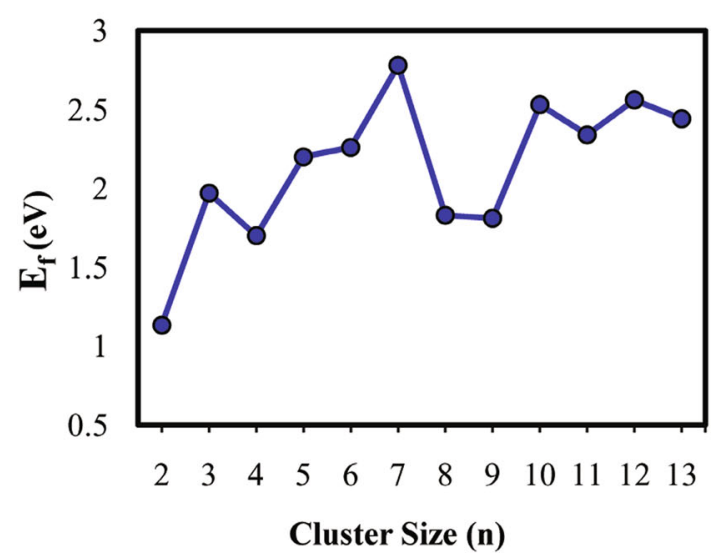

(b)

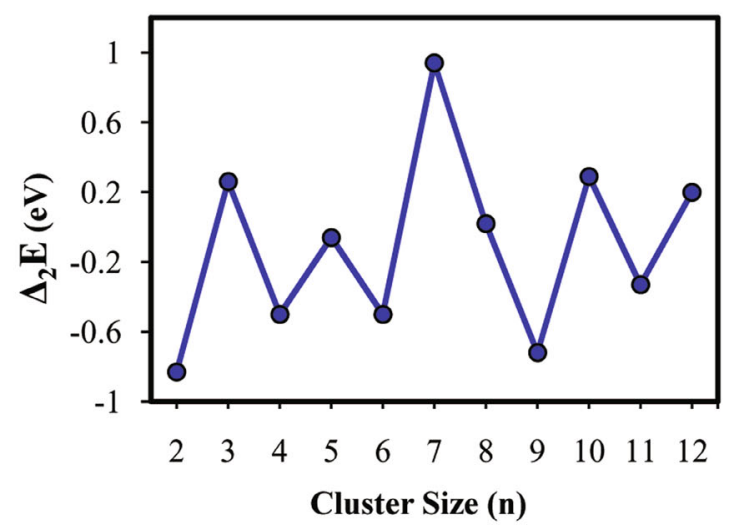

(d)

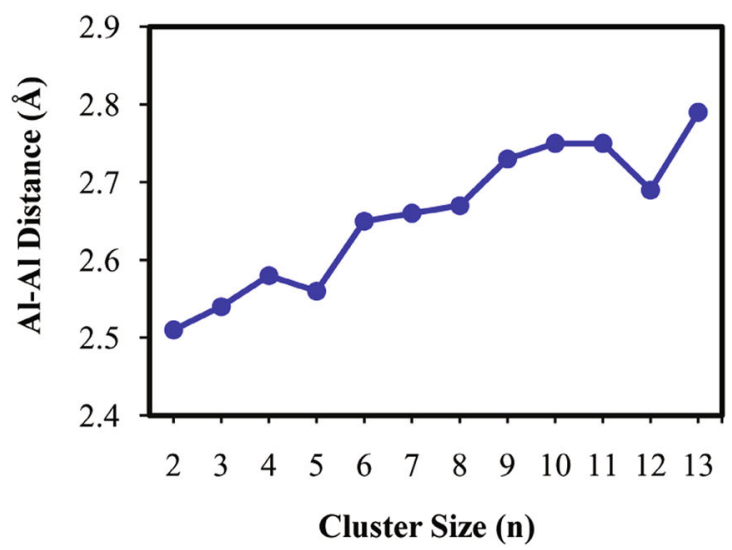

Fig. 2 Variation of binding energy per atom (a), second-order difference of cluster energies (b), fragmentation energy (c), and average Al-Al distance (d) for $\mathrm{Al}_{n}$ clusters as a function of cluster size computed at B3LYP/6-31 + G* level of theory

energy $\left(E_{\mathrm{f}}\right)$ which were calculated according to the Eqs. 2 and 3 , respectively [8].

$$
\begin{aligned}
& \Delta_{2} E\left(\mathrm{Al}_{n}\right)=E\left(\mathrm{Al}_{n+1}\right)+E\left(\mathrm{Al}_{n-1}\right)-2 E\left(\mathrm{Al}_{n}\right) \\
& E_{f}\left(\mathrm{Al}_{n}\right)=E(\mathrm{Al})+E\left(\mathrm{Al}_{n-1}\right)-E\left(\mathrm{Al}_{n}\right)
\end{aligned}
$$

where $E\left(\mathrm{Al}_{n-1}\right)$, and $E\left(\mathrm{Al}_{n+1}\right)$ are the energies of the most stable $\mathrm{Al}_{n-1}$, and $\mathrm{Al}_{n+1}$ clusters, respectively.

Figure $2 \mathrm{~b}$ presents variation of second-order difference of cluster energies $\left(\Delta_{2} E\right)$ as a function of cluster size where maxima are found at $n=3,7$, and 10 indicating more stability of these clusters compared to their neighbor clusters.

The fragmentation energy show the relative stability of clusters compared to the neighboring clusters. The higher value of fragmentation energy indicates stronger Al-Al interaction and, therefore, higher energy is required for evaporation of $\mathrm{Al}$ atom from the cluster (more stability of the cluster). According to the results of fragmentation energy $\left(E_{f}\right)$ which are shown as a function of cluster size in
Fig. 2c, it is obvious that $\mathrm{Al}_{3}, \mathrm{Al}_{7}$, and $\mathrm{Al}_{10}$ clusters are more stable than their neighbor clusters. Overall, according to the binding energies per atom, second-order difference of cluster energies, and fragmentation energies it can be concluded that $\mathrm{Al}_{7}$ is the most stable cluster among all $\mathrm{Al}_{n}$ clusters studied here.

Figure $2 \mathrm{~d}$ shows variation of average $\mathrm{Al}-\mathrm{Al}$ distance of the most stable clusters as a function of cluster size. As can be seen in this figure the average $\mathrm{Al}-\mathrm{Al}$ distance gradually increases with cluster size while having local oscillation at $\mathrm{Al}_{5}, \mathrm{Al}_{8}$ and $\mathrm{Al}_{12}$ and finally approaches the bulk limit of $2.86 \AA$ [2]. It seems that, unlike binding energy per atom, the average $\mathrm{Al}-\mathrm{Al}$ distance of the most stable $\mathrm{Al}_{n}$ clusters approaches the bulk value rather rapidly with cluster size.

The reactivity of molecules can be investigated using global (chemical) hardness $(\eta)$ [30]. Chemical hardness is defined as the second derivative of energy with respect to the number of electrons at constant external potential. 
Using the finite difference approximation chemical hardness can be expressed as, $\eta=(\mathrm{IP}-\mathrm{EA}) / 2$ [30], where IP and EA are the first ionization potential and electron affinity of the chemical system, respectively. Chemical hardness is resistance of a chemical entity to change in the number of electrons. Energetically speaking, hardness is one-half of the energy change for the disproportionation of a special chemical species according to the $S+S \rightarrow S^{+}+S^{-}$reaction [30]. Since always $\mathrm{IP}_{S} \geq \mathrm{EA}_{S}$, the minimum value of hardness is zero. Zero hardness indicates maximum softness and maximum softness means no energy change associated with the disproportionation reaction $\left(S+S \rightarrow S^{+}+S^{-}\right)$. For example, a bulk metal has IP $=$ EA $(\eta=0)$ and maximum softness [30].

The chemical hardness was calculated approximately according to the Eq. 4 [31, 32].

$\eta \cong \frac{E_{\mathrm{LUMO}}-E_{\mathrm{HOMO}}}{2}$

where $E_{\mathrm{LUMO}}$ and $E_{\mathrm{HOMO}}$ are the energies of lowest unoccupied molecular orbital (LUMO) and highest occupied molecular orbital (HOMO) respectively.

Figure 3 presents variation of chemical hardness of $\mathrm{Al}_{n}$ clusters as a function of cluster size. The general trend of Fig. 3 is oscillating behavior of the chemical hardness as a function of cluster size. Such an oscillating behavior is also reported for $\mathrm{Zr}_{n} \mathrm{O}_{2 n} \mathrm{H}_{2}$ [33], $\mathrm{Al}-\mathrm{Au}$ [34, 35], and Pd [1] clusters. According to this figure, $\mathrm{Al}_{6}$ and $\mathrm{Al}_{13}$ have the maximum hardness while $\mathrm{Al}_{2}$ and $\mathrm{Al}_{9}$ have the minimum hardness. Therefore, it can be concluded that $\mathrm{Al}_{6}$ and $\mathrm{Al}_{13}$ clusters have minimum tendency to exchange electrons (minimum reactivity) while $\mathrm{Al}_{2}$ and $\mathrm{Al}_{9}$ clusters have maximum tendency to exchange electrons (maximum reactivity).

\section{$\mathrm{Al}_{n} \mathrm{Si}_{m}$ clusters $(n=4-6, m=1-3, n+m=5-7)$}

Several possible structures for $\mathrm{Al}_{n} \mathrm{Si}_{m}$ clusters as input file at different spin multiplicities $(1,3,5$ for clusters with even

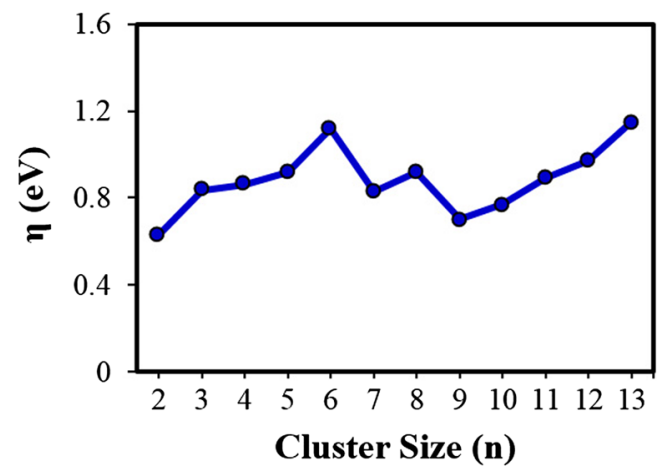

Fig. 3 Variation of chemical hardness for $\mathrm{Al}_{n}$ clusters as a function of cluster size computed at B3LYP/6-31 $+G^{*}$ level of theory electron numbers and 2, 4, 6 for clusters with odd electron numbers) were optimized at B3LYP level of theory using $6-31+G^{*}$ basis set. Figure $4 \mathrm{a}-\mathrm{c}$ presents the most stable structure of $\mathrm{Al}_{n} \mathrm{Si}_{m}$ clusters along with the corresponding spin multiplicities. Other higher energy structures along with the corresponding spin multiplicities as well as relative energies are collected as supporting information in table S.3. The calculated vibrational frequencies of most stable structures of $\mathrm{Al}_{n} \mathrm{Si}_{m}$ clusters computed at B3LYP/6$31+G^{*}$ level of theory are collected as supporting information in table S.4. Like $\mathrm{Al}_{5}$ cluster, the $\mathrm{Al}_{4} \mathrm{Si}, \mathrm{Al}_{3} \mathrm{Si}_{2}$, and $\mathrm{Al}_{2} \mathrm{Si}_{3}$ clusters have planer structures. Therefore, it seems that substitution of $\mathrm{Al}$ atom(s) with $\mathrm{Si}$ atom(s) in $\mathrm{Al}_{5}$ cluster do not change the geometry of theses clusters significantly. Unlike previous clusters, effect of $\mathrm{Al}$ atom(s) substitution with $\mathrm{Si}$ atom(s) on the geometry of $\mathrm{Al}_{6}$ is significant as clearly shown in Fig. $4 \mathrm{~b}$. While the geometry of $\mathrm{Al}_{6}$ and $\mathrm{Al}_{5} \mathrm{Si}$ is trigonal prism, the geometry of $\mathrm{Al}_{3} \mathrm{Si}_{3}$ is tetragonal bipyramid. The tetragonal bipyramid geometry has been reported as the most stable structure of pure $\mathrm{Si}_{6}$ cluster $[10,23]$. Therefore, with increasing the amount of $\mathrm{Si}$, the geometry of cluster changes from trigonal prism for pure $\mathrm{Al}_{6}$ cluster toward tetragonal bipyramid for pure $\mathrm{Si}_{6}$ cluster.

According to the Fig. 4c, substitution of $\mathrm{Al}$ atom(s) with $\mathrm{Si}$ atom(s) in $\mathrm{Al}_{7}$ cluster has also small effect on the geometry of clusters.

Effect of cluster composition on the stability of $\mathrm{Al}_{n} \mathrm{Si}_{m}$ clusters was discussed using binding energy per atom and fragmentation energy. The binding energy per atom of $\mathrm{Al}_{n} \mathrm{Si}_{m}$ clusters was calculated according to the Eq. 5 .

$E_{b}=\frac{n E(\mathrm{Al})+m E(\mathrm{Si})-E\left(\mathrm{Al}_{n} \mathrm{Si}_{m}\right)}{n+m}$

where in this equation $\mathrm{m}$ is the number of $\mathrm{Si}$ atoms in cluster, $E(\mathrm{Si})$ is the energy of $\mathrm{Si}$ atom in the most stable state and $E\left(\mathrm{Al}_{n} \mathrm{Si}_{m}\right)$ is the energy of the most stable $\mathrm{Al}_{n} \mathrm{Si}_{m}$ cluster.

Variations of binding energy per atom of $\mathrm{Al}_{n} \mathrm{Si}_{m}$ clusters as a function of atomic percentage of $\mathrm{Si}$ are shown in Fig. 5. The binding energies per atom increase linearly with adding $\mathrm{Si}$ to the pure $\mathrm{Al}_{n}$ clusters indicating that the stability of clusters can improve with increasing the amount of Si.

The fragmentation energy of $\mathrm{Al}_{n} \mathrm{Si}_{m}$ clusters was calculated according to the Eq. 6

$E_{f}\left(\mathrm{Al}_{n} \mathrm{Si}_{m}\right)=E(\mathrm{Al})+E\left(\mathrm{Al}_{n-1} \mathrm{Si}_{m}\right)-E\left(\mathrm{Al}_{n} \mathrm{Si}_{m}\right)$

Variations of fragmentation energy of $\mathrm{Al}_{n} \mathrm{Si}_{m}$ clusters as a function of atomic percentage of $\mathrm{Si}$ are shown in Fig. 6 where the most important feature is the oscillating behavior of $E_{f}$. The maxima appear in $m=3,2$, and 0 for clusters with $n+m=5,6$, and 7, respectively, indicating more 
Fig. 4 The most stable structure of $\mathrm{Al}_{n} \mathrm{Si}_{m}$ clusters along with the corresponding spin multiplicities computed at B3LYP/6-31 + $G^{*}$ level of theory

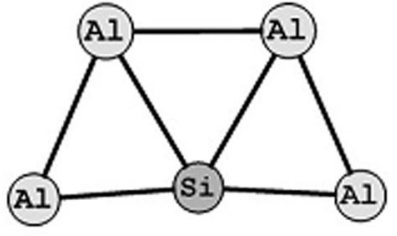

$\mathrm{Al}_{4} \mathrm{Si}(\mathrm{Ms}=1)$

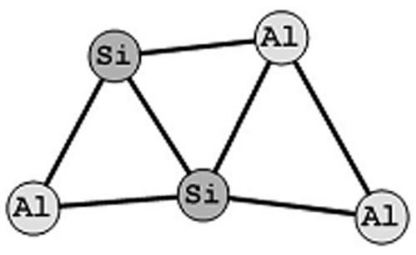

$\mathrm{Al}_{3} \mathrm{Si}_{2}(\mathrm{Ms}=2)$

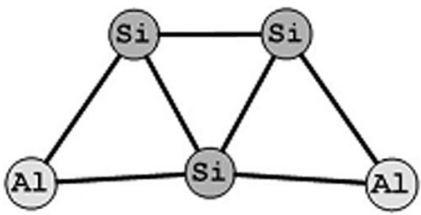

$\mathrm{Al}_{2} \mathrm{Si}_{3}(\mathrm{Ms}=1)$

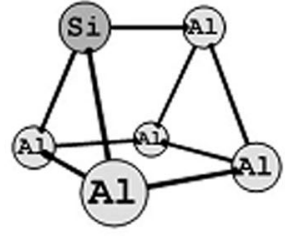

$\mathrm{Al}_{5} \mathrm{Si}(\mathrm{Ms}=2)$

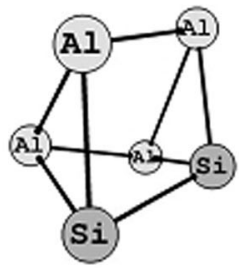

$\mathrm{Al}_{4} \mathrm{Si}_{2}(\mathrm{Ms}=1)$

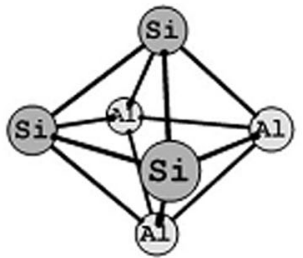

$\mathrm{Al}_{3} \mathrm{Si}_{3}(\mathrm{Ms}=\mathbf{2})$

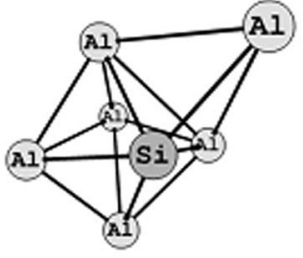

$\mathrm{Al}_{6} \mathrm{Si}(\mathrm{Ms}=1)$

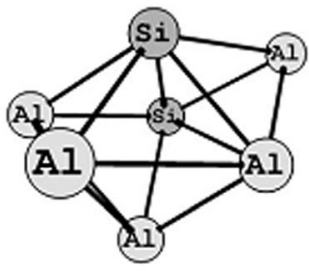

$\mathrm{Al}_{5} \mathrm{Si}_{2}(\mathrm{Ms}=\mathbf{2})$

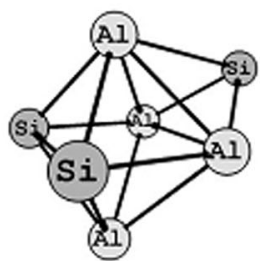

$\mathrm{Al}_{4} \mathrm{Si}_{3}(\mathrm{Ms}=1)$

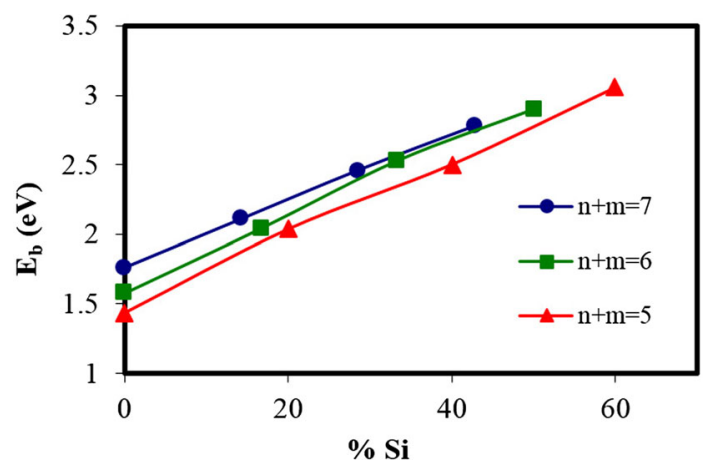

Fig. 5 Variation of binding energy per atom of $\mathrm{Al}_{n} \mathrm{Si}_{m}$ clusters as a function of atomic percentage of Si computed at B3LYP/6-31 $+G^{*}$ level of theory

stability of $\mathrm{Al}_{2} \mathrm{Si}_{3}(60 \% \mathrm{Si}), \mathrm{Al}_{4} \mathrm{Si}_{2}(33.33 \% \mathrm{Si})$, and $\mathrm{Al}_{7}$ clusters among clusters with similar number $(n+m)$ of atoms. It can be concluded that $\mathrm{Al}-\mathrm{Si}$ interaction in $\mathrm{Al}_{2} \mathrm{Si}_{3}$ and $\mathrm{Al}_{4} \mathrm{Si}_{2}$ clusters is stronger than $\mathrm{Al}-\mathrm{Al}$ interaction in $\mathrm{Al}_{5}$ and $\mathrm{Al}_{6}$ clusters, respectively, and evaporation of $\mathrm{Al}$ atom from $\mathrm{Al}_{2} \mathrm{Si}_{3}$ and $\mathrm{Al}_{4} \mathrm{Si}_{2}$ clusters requires more energy compared to the corresponding $\mathrm{Al}_{5}$ and $\mathrm{Al}_{6}$ clusters, respectively. For $\mathrm{Al}_{7}$ cluster, on the other hand, $\mathrm{Al}-\mathrm{Al}$ interaction is stronger than $\mathrm{Al}-\mathrm{Si}$ interaction in $\mathrm{Al}_{6} \mathrm{Si}$, $\mathrm{Al}_{5} \mathrm{Si}_{2}$, and $\mathrm{Al}_{4} \mathrm{Si}_{3}$ clusters and evaporation of $\mathrm{Al}$ atom

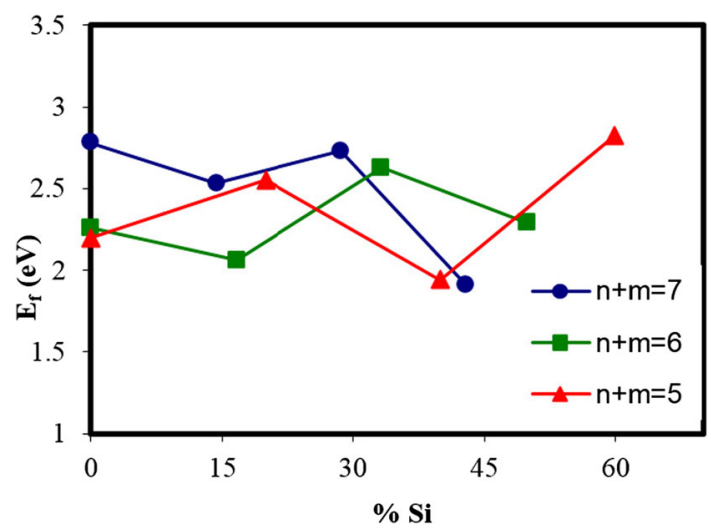

Fig. 6 Variation of fragmentation energy of $\mathrm{Al}_{n} \mathrm{Si}_{m}$ clusters as a function of atomic percentage of $\mathrm{Si}$ computed at B3LYP/6-31 + $G^{*}$ level of theory

from $\mathrm{Al}_{7}$ cluster requires more energy than $\mathrm{Al}_{6} \mathrm{Si}_{1} \mathrm{Al}_{5} \mathrm{Si}_{2}$, and $\mathrm{Al}_{4} \mathrm{Si}_{3}$ clusters.

The chemical hardness of $\mathrm{Al}_{n} \mathrm{Si}_{m}$ clusters was calculated according to the Eq. 4 and results as a function of atomic percentage of $\mathrm{Si}$ are shown in Fig. 7. The most important feature of Fig. 7 is oscillating behavior of chemical hardness as a function of atomic percentage of Si. Therefore, some of $\mathrm{Al}_{n} \mathrm{Si}_{m}$ clusters are softer than corresponding pure $\mathrm{Al}_{n}$ clusters while some others are harder. The $\mathrm{Al}_{2} \mathrm{Si}_{3}$ and 


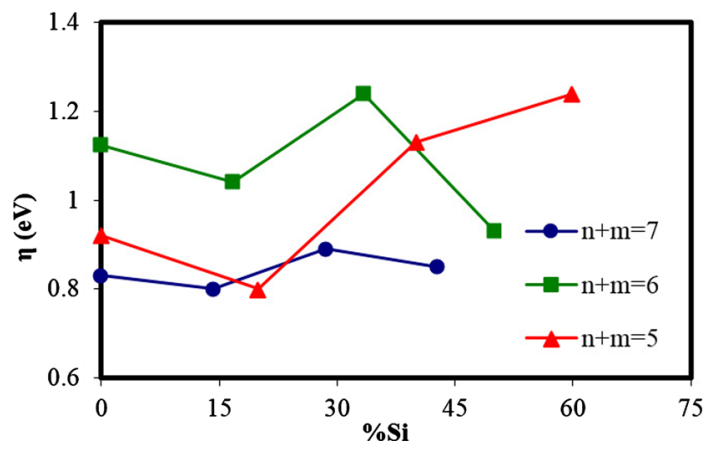

Fig. 7 Variation of chemical hardness of $\mathrm{Al}_{n} \mathrm{Si}_{m}$ clusters as a function of atomic percentage of Si computed at B3LYP/6-31 $+G^{*}$ level of theory

$\mathrm{Al}_{4} \mathrm{Si}_{2}$ clusters have the maximum values of chemical hardness among all clusters studied here.

Effect of basis set was investigated on the electronic properties of clusters considering 6-31+ $G^{*}$, 6-31 $+\mathrm{G}^{* *}$ and $6-311+\mathrm{G}^{*}$ basis sets. The calculated results are shown in Tables 2 and 3 for $\mathrm{Al}_{n}$ and $\mathrm{Al}_{n} \mathrm{Si}_{m}$ clusters, respectively. It is clear that basis set has no significant effect on the binding energy per atom, secondorder difference of cluster energies and chemical hardness of clusters. Effect of basis set on the fragmentation energy of clusters is very little, but similar trend is observed for different basis set nevertheless.

\section{Conclusions}

The geometry, stability and properties of $\mathrm{Al}_{n}(n=1-13)$ and $\mathrm{Al}_{n} \mathrm{Si}_{m}(n+m=5-7)$ nanoclusters at B3LYP level of theory using 6-31 $+G^{*}$ basis set were investigated. The binding energy per atom of pure $\mathrm{Al}_{n}$ clusters increases monotonically to the maximum value of $2.01 \mathrm{eV}$ for $\mathrm{Al}_{13}$ cluster while is smaller than the $\mathrm{Al}$ bulk cohesive energy of $3.39 \mathrm{eV}$. Analysis of binding energy per atom, secondorder difference of cluster energies, and fragmentation energy reveals that $\mathrm{Al}_{3}, \mathrm{Al}_{7}$, and $\mathrm{Al}_{10}$ clusters are more stable than their neighbor clusters. It is observed that $\mathrm{Al}_{7}$, $\mathrm{Al}_{2} \mathrm{Si}_{3}(60 \% \mathrm{Si})$ and $\mathrm{Al}_{4} \mathrm{Si}_{2}(33.33 \% \mathrm{Si})$ clusters have the maximum stability among pure and mixed clusters, respectively. Substituting of $\mathrm{Al}$ atom(s) with $\mathrm{Si}$ atom(s) change geometry of some clusters significantly while the geometry of some others remains without significant variation. Our results show that $\mathrm{Al}-\mathrm{Si}$ interaction in $\mathrm{Al}_{2} \mathrm{Si}_{3}$ and $\mathrm{Al}_{4} \mathrm{Si}_{2}$ clusters is stronger than $\mathrm{Al}-\mathrm{Al}$ interaction in $\mathrm{Al}_{5}$ and $\mathrm{Al}_{6}$ clusters, respectively, which means that evaporation of $\mathrm{Al}$ atom from $\mathrm{Al}_{2} \mathrm{Si}_{3}$ and $\mathrm{Al}_{4} \mathrm{Si}_{2}$ clusters requires more energy compared to the corresponding $\mathrm{Al}_{5}$ and $\mathrm{Al}_{6}$ clusters, respectively. For $\mathrm{Al}_{7}$ cluster, on the other hand, $\mathrm{Al}-\mathrm{Al}$ interaction is stronger than

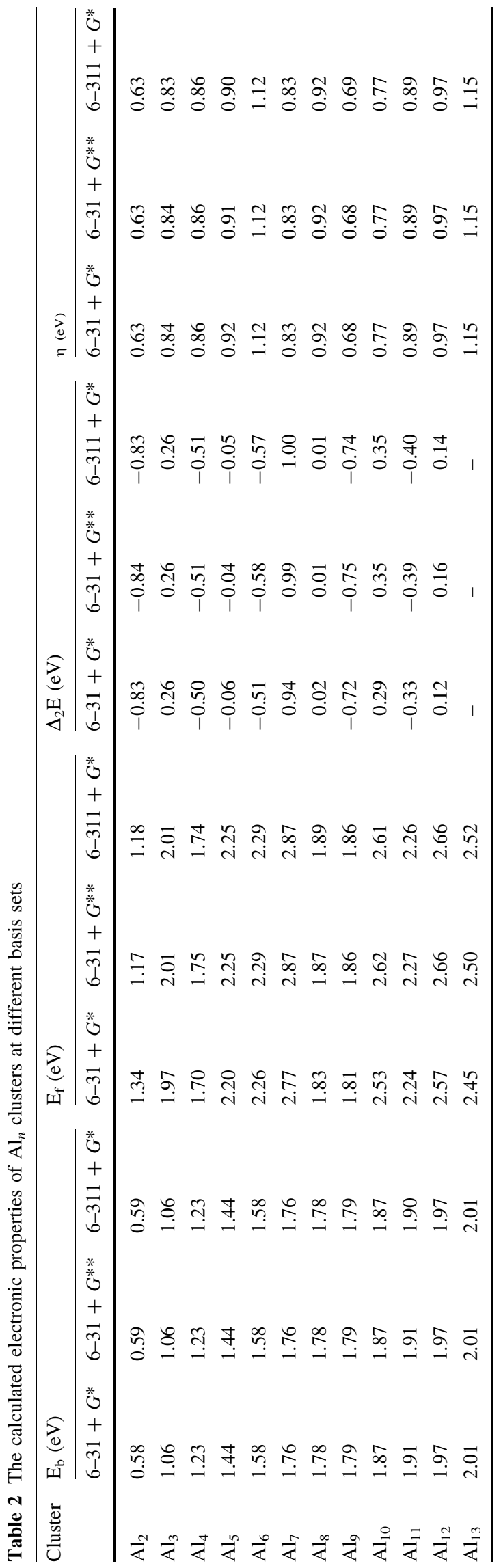


Table 3 The calculated electronic properties of $\mathrm{Al}_{n} \mathrm{Si}_{m}$ clusters at different basis sets

\begin{tabular}{|c|c|c|c|c|c|c|c|c|c|}
\hline \multirow[t]{2}{*}{ Cluster } & \multicolumn{3}{|l|}{$E_{\mathrm{b}}(\mathrm{eV})$} & \multicolumn{3}{|l|}{$E_{\mathrm{f}}(\mathrm{eV})$} & \multicolumn{3}{|l|}{$\eta(\mathrm{eV})$} \\
\hline & $6-31+G^{*}$ & $6-31+G^{* *}$ & $6-311+G^{*}$ & $6-31+G^{*}$ & $6-31+G^{* *}$ & $6-311+G^{*}$ & $6-31+G^{*}$ & $6-31+G^{* *}$ & $6-311+G^{*}$ \\
\hline $\mathrm{Al}_{4} \mathrm{Si}$ & 2.04 & 2.04 & 2.03 & 2.55 & 3.21 & 3.20 & 0.81 & 0.81 & 0.81 \\
\hline $\mathrm{Al}_{3} \mathrm{Si}_{2}$ & 2.50 & 2.50 & 2.50 & 1.94 & 1.94 & 1.92 & 1.13 & 1.13 & 1.12 \\
\hline $\mathrm{Al}_{2} \mathrm{Si}_{3}$ & 3.05 & 3.05 & 3.03 & 2.83 & 2.83 & 2.81 & 1.25 & 1.25 & 1.25 \\
\hline $\mathrm{Al}_{5} \mathrm{Si}$ & 2.04 & 2.04 & 2.04 & 2.06 & 2.06 & 2.07 & 1.04 & 1.04 & 1.04 \\
\hline $\mathrm{Al}_{4} \mathrm{Si}_{2}$ & 2.54 & 2.54 & 2.53 & 2.63 & 2.63 & 2.64 & 1.24 & 1.24 & 1.24 \\
\hline $\mathrm{Al}_{3} \mathrm{Si}_{3}$ & 2.90 & 2.93 & 2.92 & 2.29 & 2.29 & 2.31 & 0.93 & 0.93 & 0.93 \\
\hline $\mathrm{Al}_{6} \mathrm{Si}$ & 2.11 & 2.11 & 2.11 & 2.53 & 2.53 & 2.50 & 0.81 & 0.81 & 0.81 \\
\hline $\mathrm{Al}_{5} \mathrm{Si}_{2}$ & 2.46 & 2.46 & 2.45 & 2.73 & 1.96 & 1.95 & 0.89 & 0.89 & 0.89 \\
\hline $\mathrm{Al}_{4} \mathrm{Si}_{3}$ & 2.78 & 2.78 & 2.77 & 1.91 & 1.91 & 1.90 & 0.86 & 0.86 & 0.86 \\
\hline
\end{tabular}

Al-Si interaction in $\mathrm{Al}_{6} \mathrm{Si}, \mathrm{Al}_{5} \mathrm{Si}_{2}$, and $\mathrm{Al}_{4} \mathrm{Si}_{3}$ clusters indicating that evaporation of $\mathrm{Al}$ atom from $\mathrm{Al}_{7}$ cluster requires more energy than $\mathrm{Al}_{6} \mathrm{Si}, \mathrm{Al}_{5} \mathrm{Si}_{2}$, and $\mathrm{Al}_{4} \mathrm{Si}_{3}$ clusters. It is found that the chemical hardness of $\mathrm{Al}_{\mathrm{n}}$ and $\mathrm{Al}_{n} \mathrm{Si}_{m}$ clusters strongly depends on the cluster size as well as cluster composition.

Acknowledgments The Authors thank the Research Council of Semnan University for funding of this work.

Open Access This article is distributed under the terms of the Creative Commons Attribution 4.0 International License (http://crea tivecommons.org/licenses/by/4.0/), which permits unrestricted use, distribution, and reproduction in any medium, provided you give appropriate credit to the original author(s) and the source, provide a link to the Creative Commons license, and indicate if changes were made.

\section{References}

1. Wen, J.Q., Xia, T., Zhou, H., Wang, J.F.: A density functional theory study of small bimetallic $\mathrm{Pd}_{\mathrm{n}} \mathrm{Al}(\mathrm{n}=1-8)$ clusters. J. Phys. Chem. Solids 75, 528-534 (2014)

2. Rao, B.K., Jena, P.: Evolution of the electronic structure and properties of neutral and charged aluminum clusters: a comprehensive analysis. J. Chem. Phys. 111, 1890-1904 (1999)

3. Kung, H.H., Kung, M.C.: Nanotechnology: applications and potentials for heterogeneous catalysis. Catal. Today 97, 219-224 (2004)

4. Liu, Y., Hua, Y., Jiang, M., Jiang, G., Chen, J.: Theoretical study of the geometries and dissociation energies of molecular water on neutral aluminum clusters $\mathrm{Al}_{\mathrm{n}}(\mathrm{n}=2-25)$. J. Chem. Phys. 136, 084703-084709 (2012)

5. Villanueva, M.S., Hernandez, A.B., Anota, E.C., Valdez, S., Cuchill, O.V.: Electronic and structural properties of $\mathrm{Ti}_{9} \mathrm{XO}_{20}$ $(\mathrm{X}=\mathrm{Ti}, \mathrm{C}, \mathrm{Si}, \mathrm{Ge}, \mathrm{Sn}$ and $\mathrm{Pb}$ ) clusters: a DFT study. Phys. E 65, $120-124$ (2015)

6. Arab, A., Gobal, F., Nahali, N., Nahali, M.: Electronic and structural properties of neutral, anionic, and cationic $\mathrm{Rh}_{\mathrm{x}} \mathrm{Cu}_{4--}$ $\mathrm{x}(\mathrm{x}=0-4)$ small clusters: a DFT study. J. Clust. Sci. 24, 273-287 (2013)
7. Guo, L.: Density functional study of structural and electronic properties of $\mathrm{Al}_{n} \mathrm{As}(1 \leq n \leq 15)$ clusters. J. Alloy. Compd. 527, 197-203 (2012)

8. Feng, X.J., Luo, Y.H.: Structure and stability of Al-doped boron clusters by the density-functional theory. J. Phys. Chem. A 111, 2420-2425 (2007)

9. Zhang, W., Han, Y., Yao, S., Sun, H.: Stability analysis and structural rules of titanium dioxide clusters $\left(\mathrm{TiO}_{2}\right)_{\mathrm{n}}$ with $\mathrm{n}=1-9$. Mater. Chem. Phys. 130, 196-202 (2011)

10. Ding, W.F., Li, B.X.: A first-principles study of $\mathrm{Al}_{\mathrm{n}} \mathrm{Si}_{\mathrm{m}-\mathrm{n}}$ clusters $(\mathrm{m}=6,9,10 ; \mathrm{n} \leqslant \mathrm{m})$. J. Mol. Struct. Theochem. 897, 129-138 (2009)

11. Akola, J., Hakkinen, H., Manninen, M.: Ionization potential of aluminum clusters. Phys. Rev. B. 58, 3601-3604 (1998)

12. Viet Bac, P.T., Ogawa, H.: Hydrogen atom adsorption on aluminum icosahedral clusters: a DFT study. J. Alloy. Compd. 509, S675-S678 (2011)

13. Guo, L., Yang, Y.: Theoretical investigation of molecular hydrogen adsorption and dissociation on $\mathrm{Al}_{\mathrm{n}} \mathrm{V}(\mathrm{n}=1-13)$ clusters. Int. J. Hydrogen Energ. 38, 3640-3649 (2013)

14. Fuke, K., Nonose, S., Kikuchi, N., Kaya, K.: Reaction of aluminum clusters, $\mathrm{Al}_{\mathrm{n}}(\mathrm{n}=7-24)$, with oxygen and ammonia. Chem. Phys. Lett. 147, 479-483 (1988)

15. Reber, A.C., Roach, P.J., Woodward, W.H., Khanna, S.N., Castleman, A.W.: Edge-induced active sites enhance the reactivity of large aluminum cluster anions with alcohols. J. Phys. Chem. A 116, 8085-8091 (2012)

16. Das, S., Pal, S., Krishnamurty, S.: Understanding the site selectivity in small-sized neutral and charged $\mathrm{Al}_{\mathrm{n}}(4 \leq \mathrm{n} \leq 7)$ clusters using density functional theory based reactivity descriptors: a validation study on water molecule adsorption. J. Phys. Chem. A 117, 8691-8702 (2013)

17. Pino, I., Kroes, G.J., Van Hemert, M.C.: Hydrogen dissociation on small aluminum clusters. J. Chem. Phys. 133, 184304-184312 (2010)

18. Yarovskya, I., Goldberg, A.: DFT study of hydrogen adsorption on $\mathrm{Al}_{13}$ clusters. Mol. Simul. 31, 475-481 (2005)

19. Xiang, H., Kang, J., Wei, S.H., Kim, Y.H., Curtis, C., Blake, D.: Shape control of Al nanoclusters by ligand size. J. Am. Chem. Soc. 131, 8522-8526 (2009)

20. Mosch, C., Koukounas, C., Bacalis, N., Metropoulos, A., Gross, A., Mavridis, A.: Interaction of dioxygen with $\mathrm{Al}$ clusters and Al(111): a Comparative Theoretical Study. J. Phys. Chem. C 112, 6924-6932 (2008)

21. Kumar, V., Bhattacharjee, S., Kawazoe, Y.: Silicon-doped icosahedral, cuboctahedral, and decahedral clusters of aluminum. Phys. Rev. B. 61, 8541-8547 (2000) 
22. Majumder, C., Kulshreshtha, S.K.: Influence of Al substitution on the atomic and electronic structure of $\mathrm{Si}$ clusters by density functional theory and molecular dynamics simulations. Phys. Rev. B. 69, 115432-115439 (2004)

23. Li, B.X., Wang, G.Y., Ye, M.Y., Yang, G., Yao, C.H.: Geometric and energetic properties of Al-doped $\mathrm{Si}_{\mathrm{n}}(\mathrm{n}=2-21)$ clusters: FPLMTO-MD calculations. J. Mol. Struct. Theochem. 820, 128-140 (2007)

24. Becke, A.D.: Density-functional exchange-energy approximation with correct asymptotic behavior. Phys. Rev. A 38, 3098-3100 (1988)

25. Lee, C., Yang, W., Parr, R.G.: Development of the Colle-Salvetti correlation-energy formula into a functional of the electron density. Phys. Rev. B 37, 785-789 (1988)

26. Frisch, M.J., et al.: Gaussian 03, Revision B.03. Gaussian, Inc., Pittsburgh, PA (2003)

27. Cox, D.M., Trevor, D.J., Whetten, R.L., Rohlfing, E.A., Kaldor, A.: Aluminum clusters: magnetic properties. J. Chem. Phys. 84, 4651-4656 (1986)

28. Curotto, V.F., Diez, R.P.: Density functional study on the geometric features and growing pattern of $\mathrm{Al}_{\mathrm{n}} \mathrm{N}_{\mathrm{m}}$ clusters $(\mathrm{n}=1-4$, $\mathrm{m}=1-4, \mathrm{n}+\mathrm{m} \leqslant 5)$. Comp. Mater. Sci. 50, 3390-3396 (2011)

29. Zheng, X., Zhang, Y., Huang, S., Liu, H., Wang, P., Tian, H.: DFT study of structural, electronic and vibrational properties of pure $\left(\mathrm{Al}_{2} \mathrm{O}_{3}\right)_{\mathrm{n}}(\mathrm{n}=9,10,12,15)$ and Ni-doped $\left(\mathrm{Al}_{2} \mathrm{O}_{3}\right)_{\mathrm{n}}(\mathrm{n}=9$, 10) clusters. Appl. Surf. Sci. 257, 6410-6417 (2011)

30. Parr, R.G., Pearson, R.G.: Absolute hardness: companion parameter to absolute electronegativity. J. Am. Chem. Soc. 105, 7512-7516 (1983)

31. Tozer, D.J., Proft, F.D.: Computation of the hardness and the problem of negative electron affinities in density functional theory. J. Phys. Chem. A 109, 8923-8929 (2005)

32. Chandra, A.K., Uchimaru, T.: Hardness profile: a Critical Study. J. Phys. Chem. A 105, 3578-3582 (2001)

33. Jin, R., Zhang, S., Zhang, Y., Huang, S., Wang, P., Tian, H.: Theoretical investigation of adsorption and dissociation of $\mathrm{H}_{2}$ on $\left(\mathrm{ZrO}_{2}\right)_{\mathrm{n}} \quad(\mathrm{n}=1-6)$ clusters. Int. J. Hydrogen Energ. 36, 9069-9078 (2011)

34. Paranthaman, S., Hong, K., Kim, J., Kim, D.E., Kim, T.K.: Density functional theory assessment of molecular structures and energies of neutral and anionic $\mathrm{Al}_{\mathrm{n}}(\mathrm{n}=2-10)$ Clusters. J. Phys. Chem. A 117, 9293-9303 (2013)

35. Wang, C., Kuang, X., Wang, H., Li, H., Gu, J., Liu, J.: Densityfunctional investigation of the geometries, stabilities, electronic, and magnetic properties of gold cluster anions doped with aluminum: $A u_{n} A l^{-}(1 \leqslant \mathrm{n} \leqslant 8)$. Comput. Theor. Chem. 1002, 31-36 (2012) 